\title{
PENGARUH ATURAN ETIKA TERHADAP KUALITAS AUDIT YANG DIMEDIASI OLEH PENGENDALIAN MUTU (SURVEI PADA AUDITOR BPK RI)
}

\author{
Claudia Wanda Melati Korompis ${ }^{1}$ \\ ${ }^{1}$ Jurusan Akuntansi, Fakultas Ekonomi dan Bisnis, Universitas Sam Ratulangi, Jl. Kampus Bahu. Manado, \\ 95115, Indonesia \\ email : wanda_korompis@yahoo.co.id
}

\begin{abstract}
The fraud cases involving government auditors certainly erode public trust. The importance of improving audit quality to increase the public trust makes author interested in conducting research that seeks to measure the determinants of audit quality. Before Enron and Worldcom's accounting scandal on 2001-2002, studies that measured audit quality generally still use KAP-size proxies. DeAngelo's (1981: 186), states that: "The quality of audit services is defined as a market-assessed joint venture, which will both (a) discover a breed of client's accounting system, and (b) report the breach". Ethical rules become independent variables in this study. In addition, author also added Expectancy Theory to mediate the relationship between ethical rules and audit quality represented by quality control variables. This model was inspired by Aldhizer et al. (1995) where the measure of audit quality can also be assessed from how much the level of adherence and appropriateness of the client's financial statements to the rules, laws, and applicable standards. The results of the study indicate that ethical rules have an influence on audit quality by mediating by quality control.
\end{abstract}

Keywords : Ethics, Control, Audit.

\section{PENDAHULUAN}

Indonesia Corruption Watch (ICW) menilai bahwa dalam kurun waktu 2005-2017 kurang lebih terdapat enam kasus suap dimana melibatkan 23 auditor, pejabat dan staff BPK. Beberapa diantaranya terjadi pada tahun 2010-2011 dalam proyek pembangunan sarana olahraga terpadu di Hambalang Bogor oleh Kemenpora, dimana terjadi kerugian Negara sebesar Rp.471 miliar. Kasus kecurangan juga terjadi tahun 2016 pada beberapa pemerintah kabupaten dan kota di Sulawesi Utara. Pejabat Pemkab dan Pemkot ditenggarai memberikan dana sejumlah Rp.1,6 miliar guna diloloskannya laporan hasil pemeriksaaan mereka. Operasi tangkap tangan (OTT) KPK tahun 2017 juga berhasil menangkap sejumlah auditor BPK yang terkena suap oleh Kementerian Desa, Pembangunan Daerah Tertinggal dan Transmigrasi (Kemendesa) terhadap laporan keuangan Kemendesa tahun 2016. Kasus-kasus kecurangan yang melibatkan auditor-auditor pemerintah tersebut membuat masyarakat ragu akan kinerja auditor. Masyarakat menilai ternyata melalui kasus-kasus tersebut, opini audit dapat direkayasa walaupun sudah ada sejumlah standar baku pada pelaksanaan proses audit. Pemberian opini bisa dimanipulasi dan mengakibatkan kerugian bagi Negara. Opini audit yang berhasil dimanipulasi membuat kualitas audit menjadi buruk dimata masyarakat.

Kualitas dari suatu audit menjadi tolak ukur kualitas auditor itu sendiri. Profesi auditor merupakan salah satu profesi kepercayaan publik untuk menilai baik atau tidak baiknya kondisi keuangan organisasi. Profesi ini dapat dikatakan bertanggungjawab maupun tidak dilihat dari hasil pemeriksaan maupun opini atas evidential matter yang diperiksa. Pentingnya meningkatkan kualitas audit untuk memperbaiki kepercayaan masyarakat membuat peneliti tertarik untuk melakukan penelitian yang berusaha untuk mengukur determinan kualitas audit. Peneliti umumnya mendasarkan pengukuran kualitas audit pada penelitian DeAngelo (1981) yang menggunakan ukuran kantor akuntan publik sebagai proksi 
kualitas audit dalam penelitiannya. Pengukuran kualitas audit yang dilakukan DeAngelo sepertinya memaksakan ukuran kantor akuntan publik sebagai proksi bagi kualitas audit.

Sebelum terjadi skadal akuntansi Enron dan Worldcom tahun 2001-2002, penelitian yang mengukur kualitas audit umumnya masih menggunakan proxy ukuran KAP. Dye (1991) menyatakan bahwa KAP dengan aset yang lebih besar menghasilkan laporan audit yang lebih kredibel dibandingkan KAP yang mempunyai aset yang lebih kecil. Lennox (1999) mengungkapkan bahwa KAP yang besar lebih berkemampuan menangkap signal kecurangan keuangan yang terjadi dan mengungkapnya dalam laporan audit mereka. Setelah terjadinya skandal akuntansi tersebut, determinan kualitas audit menjadi semakin beragam.

Persepsi yang berbeda-beda tersebut di atas terhadap kualitas audit berdampak terhadap berbagai studi yang dilakukan, di antaranya ukuran dan spesialisasi auditor (Behn, Choi, Kang, 2008), tenur auditor (Carcello dan Nagy, 2004; Ghosh dan Moon, 2005; Carey dan Simnett, 2006; Bedard dan Johnstone, 2010), reputasi auditor (Skinner dan Srinivasan, 2012), judgment audit (Libby dan Luft, 1993), dan audit firm characteristics (Tritschler, 2013). Beberapa studi yang dilakukan berusaha memberikan alasan rasional dan justifikasi setepat mungkin, mengapa konstruk atau variabel tertentu mewakili kualitas audit. Bahkan, Deis dan Giroux (1992) dalam studinya menggabungkan beberapa variabel, seperti peer review, tenur, jumlah jam, jumlah klien, dan kesehatan keuangan klien sebagai indikator untuk menilai apakah audit telah berjalan secara berkualitas.

Sebenarnya determinan kualitas audit telah tergambar dengan jelas pada pernyataan DeAngelo (1981 : 186) yaitu : "The quality of audit services is defined to be the marketassessed joint probability that a given auditor will both (a) discover a breach in the client's accounting system, and (b) report the breach.". Audit dinilai berkualitas apabila para auditor dapat menunjukkan kemampuannya untuk menemukan dan melaporkan terjadinya kesalahan atau kecurangan material dalam laporan keuangan dan sistem akuntansi klien. Pernyataan diatas sejalan dengan Elitzur dan Falk (1996) yang menyatakan bahwa kredibilitas auditor bergantung pada: 1) probabilitas auditor melakukan deteksi kesalahan yang material dan kesalahan dalam penyajian, dan 2) probabilitas auditor melaporkan salah saji yang ditemukannya.

Aturan etika dipandang penting oleh peneliti sebagai prinsip dasar yang harus ada dalam diri seorang auditor. Standar Pemeriksaan Keuangan Negara (SPKN : 2017) menyebutkan bahwa terdapat sejumlah prinsip-prinsip dalam pemeriksaan keuangan Negara sebagai aturan yang harus dimengerti dan dilaksanakan dengan baik oleh pembuat standar dalam penyusunan standar pemeriksaan dan pemeriksa dalam melaksanakan pemeriksaan. Salah satunya adalah kode etik dimana menurut SPKN (2017) dalam mewujudkan Badan Pemeriksa Keuangan (BPK) yang independen, memiliki integritas dan profesionalisme bagi kepentingan Negara, semua anggota BPK dan pemeriksa keuangan Negara harus taat pada kode etik. Kode etik ditetapkan oleh BPK yang terdiri dari Independensi, Intergritas dan Profesionalisme.

Independensi merupakan sikap serta tindakan dalam melakukan Pemeriksaan yang tidak berpihak dan tidak dipengaruhi siapapun. Pemeriksa wajib bersikap objektif dan terbebas dari konflik kepentingan (conflict of interest) dalam melakukan tanggung jawab profesinya. Auditor memiliki kewajiban menerapkan independensi melalui pemikiran (independence of mind) serta independensi dalam penampilannya (independence in appearance). Integritas didefinisikan sebagai kualitas, sifat, atau kondisi yang memperlihatkan kesatuan yang utuh, sifat yang jujur, pekerja keras, serta kompetensi yang baik. Profesionalisme merupakan kemampuan, keahlian, dan komitmen profesi dalam melaksanakan tugas dengan prinsip kehati-hatian (due care), ketelitian, dan kecermatan, juga bersandar pada standar dan undang-undang yang berlaku. Sikap profesionalisme auditor terwujud juga melalui skeptisisme profesional (professional skepticism) saat pemeriksaan 
serta mengutamakan prinsip pertimbangan profesional (professional judgment). Dengan adanya aturan etika ini diharapkan auditor dapat membuat pertimbangan yang tepat untuk menemukan salah saji yang ada dalam laporan keuangan auditee serta melaporkan hasil temuannya dengan mengeluarkan laporan hasil pemeriksaan.

Selain itu, ukuran kualitas audit dapat pula dinilai dari seberapa besar tingkat ketaatan dan kesesuaian laporan keuangan klien terhadap aturan, hukum, dan standar-standar yang berlaku (Aldhizer dkk., 1995; GAO, 2003). SPKN (2017) menyatakan bahwa kepercayaan pemangku kepentingan akan meningkat atas hasil pemeriksaan BPK, sehingga dibutuhkan standar pengendalian mutu. Sistem pengendalian mutu Badan Pemeriksa Keuangan harus sejalan dengan standar pengendalian mutu agar kualitas pemeriksaan terjaga. Sistem pengendalian mutu meliputi, namun tak terbatas pada supervisi, review berjenjang, monitoring, dan konsultasi dalam kegiatan pemeriksaan. Pengendalian mutu dinilai sebagai pemediasi hubungan antara aturan etika dan kualitas audit karena menurut SPKN (2017) Badan pemeriksa keuangan wajib membuat suatu pengendalian mutu guna memastikan kualitas hasil pemeriksaan. Sistem pengendalian mutu terdiri dari hal-hal seperti prosedur dan kebijakan yang bertujuan agar laporan hasil pemeriksaan bermutu tinggi dan sesuai dengan standar pemeriksaan dan undang-undang. Auditor wajib memiliki sejumlah aturan etika yang memadai dan kemudian menerapkan sistem pengendalian mutu yang sesuai agar keyakinan terhadap kualitas laporan hasil pemeriksaan yang dikeluarkan nanti bermanfaat bagi pengguna laporan tersebut dalam membuat berbagai kebijakan ekonomi.

\section{TINJAUAN PUSTAKA}

Aturan Etika. Standar Pemeriksaan Keuangan Negara (2017) menyatakan bahwa anggota BPK dan Pemeriksa wajib melakukan pemeriksaan menurut prinsip-prinsip etika sebagai bagian penting dalam nilai akuntabilitas serta ekspektasi publik terhadap BPK dan Auditor dalam melakukan pemeriksaan. Anggota BPK dan Auditor dalam melakukan tugas dan wewenangnya wajib taat kepada prinsip-prinsip etika yakni independensi, integritas, dan profesionalisme sebagai nilai-nilai dasar BPK. Dalam mewujudkan BPK yang independen, berintegritas, dan profesional bagi kepentingan negara, Anggota BPK dan Pemeriksa Keuangan Negara harus taat kepada kode etik. Kode etik merupakan norma-norma yang harus ditaati oleh semua Anggota BPK dan Pemeriksa Keuangan Negara dalam melakukan tugasnya guna menjaga martabat, kehormatan, citra, serta kredibilitas BPK. Independensi, integritas, dan profesionalisme merupakan nilai-nilai yang harus dipatuhi oleh Anggota BPK dan Pemeriksa Keuangan Negara. Auditor wajib menerapkan kemahiran profesional dengan cermat dan seksama, skeptisisme profesional, serta pertimbangan profesional pada semua kegiatan pemeriksaan.

Pengendalian Mutu. Sistem pengendalian mutu adalah prosedur dan kebijakan guna memastikan didapatnya hasil audit yang berkualitas tinggi sesuai standar pemeriksaan dan undang-undang yang berlaku. Diperlukan standar pengendalian mutu untuk meningkatkan kepercayaan stakeholder terhadap hasil audit BPK. Sistem pengendalian mutu BPK harus dilaksanakan agar supaya kualitas pemeriksaan yang dilakukan tetap terjaga. Sistem pengendalian mutu mencakup kegiatan-kegiatan seperti supervisi, review berjenjang, monitoring, serta konsultasi selama pemeriksaan. Sistem pengendalian mutu BPK dikaji secara internal, juga oleh badan pemeriksa keuangan dari negara lain sebagai anggota organisasi pemeriksa keuangan dunia. Pemeriksa wajib mempraktekkan sistem pengendalian mutu saat diberikan penugasan untuk memberikan keyakinan memadai bahwa kegiatan Pemeriksaan telah sesuai dengan standar pemeriksaan serta aturan undang-undang, dan LHP tepat sesuai dengan kondisinya. BPK wajib menetapkan dan mengembangkan sistem pengendalian mutu guna memastikan proses Pemeriksaan telah sejalan dengan standar pemeriksaan serta aturan perundang-undangan (SPKN : 2017). 
Kualitas Audit. Kualitas audit dapat dicapai apabila seorang akuntan kemungkinan menemukan dan melaporkan terjadinya suatu penyelewengan yang terjadi. Menemukan penyelewengan ini dibutuhkan pengalaman, pendidikan, profesionalisme, dan pengetahuan akan struktur audit perusahaan. Selain itu juga tergantung pada independensi akuntan. DeAngelo (1981b) menyatakan bahwa audit yang berkualitas dinilai dari kemampuan auditor menemukan dan melaporkan adanya salah saji yang material dalam laporan keuangan klien. Pengertian kualitas audit yang dikemukakan oleh DeAngelo (1981b) tersebut menjadi rujukan dalam beberapa studi, antara lain (Palmrose, 1988; Deis dan Giroux, 1992), bahwa kualitas audit ditunjukkan oleh dua kemampuan auditor, yaitu menemukan kesalahan dan melaporkannya. Definisi kualitas audit ini menunjukkan dua kemampuan auditor sekaligus, yakni kompetensi untuk menemukan kesalahan dan kecurangan serta sikap mental independen untuk melaporkan kesalahan material yang terdapat dalam sistem akuntansi dan laporan keuangan klien. Selain itu, ukuran kualitas audit dapat pula dinilai dari seberapa besar tingkat ketaatan dan kesesuaian laporan keuangan klien terhadap aturan, hukum, dan standar-standar yang berlaku (Aldhizer dkk., 1995; GAO, 2003).

\section{Rerangka Konseptual dan Hipotesis}

Rerangka Konseptual Penelitian. Gambar 1 menunjukkan bagaimana rerangka konseptual yang peneliti tawarkan. Dimana gambar ini menunjukkan arah penelitian awal peneliti-peneliti yang sebagian besar berfokus pada audit judgment sebagai kemampuan yang dimiliki seseorang yang dikembangkan dalam rangka meningkatkan kualitas audit dengan human capital theory sebagai grand theory. Peneliti kemudian menambahkan Expectancy Theory untuk memediasi hubungan antara aturan etika dan kualitas audit yang diwakili oleh variabel pengendalian mutu. Teori Harapan (expectancy) menilai bahwa intensitas melakukan suatu usaha dengan cara tertentu akan mengarahkan seseorag untuk mencapai tujuannya. Jadi menurut peneliti kemampuan yang dimiliki, membuat seseorang semakin terpacu untuk bekerja keras dalam rangka mencapai hasil yang lebih baik.

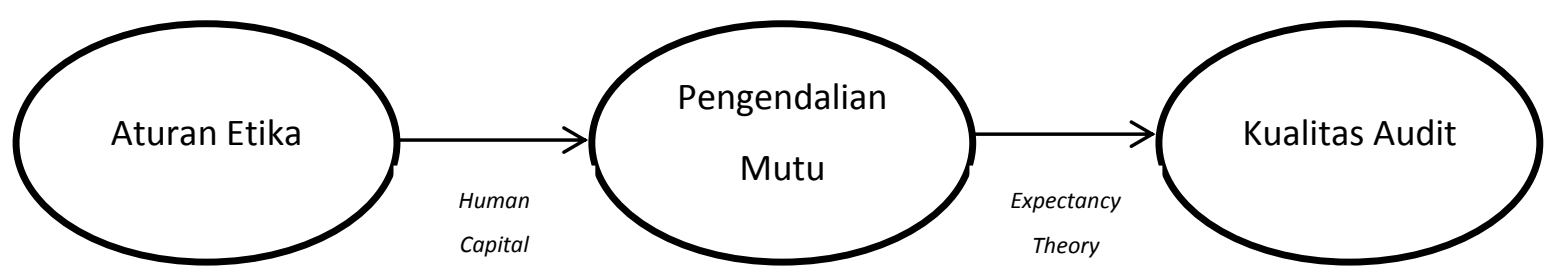

Gambar 1. Rerangka Konseptual Penelitian

Hipotesis. Modal manusia memiliki berbagai dimensi yang dikategorikan sebagai kelebihan-kelebihan yang dimiliki oleh individu, termasuk keahlian dan kemampuan, penampilan, reputasi, atau berupa sikap kepedulian terhadap kepentingan umum, sehingga memunculkan kepercayaan dari masyarakat. Human capital (HC) dianggap sebagai kombinasi antara inteligensi, keterampilan, dan keahlian yang mewarnai individu dan organisasi yang dikelompokkan ke dalam tiga kategori: kompentensi, sikap, dan kemampuan intelektual (Bontis dkk., 1999). Dengan prinsip-prinsip dasar etika yang dimiliki diharapkan auditor mampu memberikan hasil audit yang berkualitas melalui pelaporan yang andal dan kredibel. DeAngelo (1981) menyatakan bahwa audit dinilai berkualitas apabila para auditor dapat menunjukkan kemampuannya untuk menemukan dan melaporkan terjadinya kesalahan atau kecurangan material dalam laporan keuangan dan sistem akuntansi klien. Auditor harus membuat pertimbangan yang tepat dengan memanfaatkan kemampuan dasar yang dimilikinya kemudian melaporkannya ke dalam laporan hasil pemeriksaan sesuai dengan prinsip etika seperti independensi, integritas dan profesionalisme. Expectancy Theory 
merupakan suatu teori hubungannya dengan motivasi individu atau dapat didefinisikan juga sebagai teori harapan. Teori ini menjelaskan bahwa kecenderungan untuk melakukan suatu usaha dengan cara bertentu tergantung pada harapan bahwa suatu kinerja akan diikuti dengan hasil yang baik serta pada daya tarik hasil yang ditujukan oleh seseorang. Teori ini mengemukakan bahwa individu-individu akan termotivasi dalam melakukan hal tertentu untuk meraih tujuan jika mereka tahu bahwa tindakan mereka akan mengarahkan mereka kepada pencapaian tujuan (harapan) tersebut. Vroom's Expectancy Theory (1964) menyatakan bahwa perilaku yang diharapkan akan semakin meningkat apabila orang tersebut merasakan ada hubungan positif antara usaha yang dilakukan dengan hasil yang dicapai. Manusia akan termotivasi untuk secara intens melakukan hal-hal yang dapat meningkatkan prestasinya. Ketika manusia sadar bahwa dia memiliki kemampuan tertentu yang dapat dikembangkan untuk meraih hasil yang baik, maka dia akan termotivasi dalam pencapaian tujuan akhirnya. Pengendalian mutu sebagai suatu sistem dalam pemeriksaan yang terdiri dari supervisi, review berjenjang, monitoring, dan pelaksanaan konsultasi selama proses pemeriksaan. Kegiatan ini dianggap sangat penting untuk mewujudkan hasil yang baik dalam audit yang dilaksanakan.

H1 : Ada Pengaruh Aturan Etika terhadap Pengendalian Mutu

H2 : Ada Pengaruh Pengendalian Mutu terhadap Kualitas Audit

H3 : Ada Pengaruh Aturan Etika terhadap Kualitas Audit

H4 : Ada Pengaruh Aturan Etika yang dimediasi oleh Pengendalian Mutu terhadap Kualitas Audit

\section{METODE PENELITIAN}

Populasi dan Sampel. Sampel dari penelitian ini adalah Auditor BPK RI di Jakarta. Metode survei penelitian ini adalah mail survey dengan bantuan aplikasi google form. Responden yang telah meng-submit hasil survei sebanyak 31 orang. Sebelumnya peneliti telah melakukan pre-test untuk meyakinkan bahwa instrument yang digunakan valid dan reliable. Pre-test dilakukan pada 30 mahasiswa S3 Program Doktor Ilmu Akuntansi yang berprofesi sebagai Dosen sekaligus pernah/masih berprofesi sebagai Auditor/Akuntan.

Model Analisis. Model analisis penelitian ini menggunakan analisis jalur (path analysis). Model jalur adalah suatu diagram yang menghubungkan antara konstruk. Analisis jalur digunakan oleh peneliti karena dua alasan. Pertama, analisis jalur merupakan structural equation yang bersifat recursive. Kedua, peneliti menganalisis hubungan sebab akibat yang terjadi, dalam konteks konstruk independen mempengaruhi konstruk dependen bukan hanya secara langsung namun juga secara tidak langsung. Model Persamaan structural adalah sebagai berikut :

$$
\eta(\text { Kualitas Audit })=\gamma 1 \text { AturanEtika }+\beta 1 \text { PengendalianMutu }+e
$$

Pengujian Hipotesis. Analisis structural equation modeling (SEM) dalam penelitian ini diterapkan dengan menggunakan program warp PLS versi 6.0 untuk menguji hipotesis. Alat analisis ini diterapkan dalam penelitian ini karena memiliki beberapa kelebihan. Pertama, menurut peneliti SEM-PLS cocok bagi model penelitian ini yang memakai variabel laten dan juga telah memperhitungkan nilai measurement error. Kedua, analisis SEM-PLS bisa menguji secara simultan multiple dependence bgai model penelitian ini. Ketiga, component-based SEM-PLS bisa mengestimasi model yang rumit dengan jumlah sampel yang kecil.

\section{HASIL PENELITIAN DAN PEMBAHASAN \\ 4.1. Gambaran Objek Penelitian}


Berikut disajikan gambaran umum objek penelitian yaitu Auditor BPK-RI di Jakarta :

Tabel 1 Komposisi Responden Berdasarkan Jenis Kelamin

\begin{tabular}{ccc}
\hline Jenis Kelamin & Jumlah & Presentase \\
\hline Laki - laki & 20 & $65 \%$ \\
Wanita & 11 & $35 \%$ \\
Jumlah & 31 & $100 \%$ \\
\hline
\end{tabular}

Sumber : Data Hasil Olahan, 2018

Tabel 2 Komposisi Responden Berdasarkan Pendidikan Terakhir

\begin{tabular}{ccc}
\hline Jenis Kelamin & Jumlah & Presentase \\
\hline S1 & 21 & $68 \%$ \\
S2 & 9 & $29 \%$ \\
S3 & 1 & $3 \%$ \\
Jumlah & 31 & $100 \%$ \\
\hline
\end{tabular}

Sumber : Data Hasil Olahan, 2018

Tabel 3 Komposisi Responden Berdasarkan Umur

\begin{tabular}{ccc}
\hline Jenis Kelamin & Jumlah & Presentase \\
\hline $21-30$ & 14 & $45 \%$ \\
$31-40$ & 16 & $52 \%$ \\
$41-50$ & 1 & $3 \%$ \\
Jumlah & 31 & $100 \%$ \\
\hline
\end{tabular}

Sumber : Data Hasil Olahan, 2018

Tabel 4 Komposisi Responden Berdasarkan Lama Bekerja

\begin{tabular}{ccc}
\hline Jenis Kelamin & Jumlah & Presentase \\
\hline $1-2$ tahun & 1 & $3 \%$ \\
$>2$ tahun & 30 & $97 \%$ \\
Jumlah & 31 & $100 \%$ \\
\hline
\end{tabular}

Sumber : Data Hasil Olahan, 2018

Tabel 5 Model Fit dan Quality Indices

\begin{tabular}{lllll}
\hline No. & Model Fit dan Quality Indices & Kriteria Fit & Hasil & Ket. \\
\hline
\end{tabular}




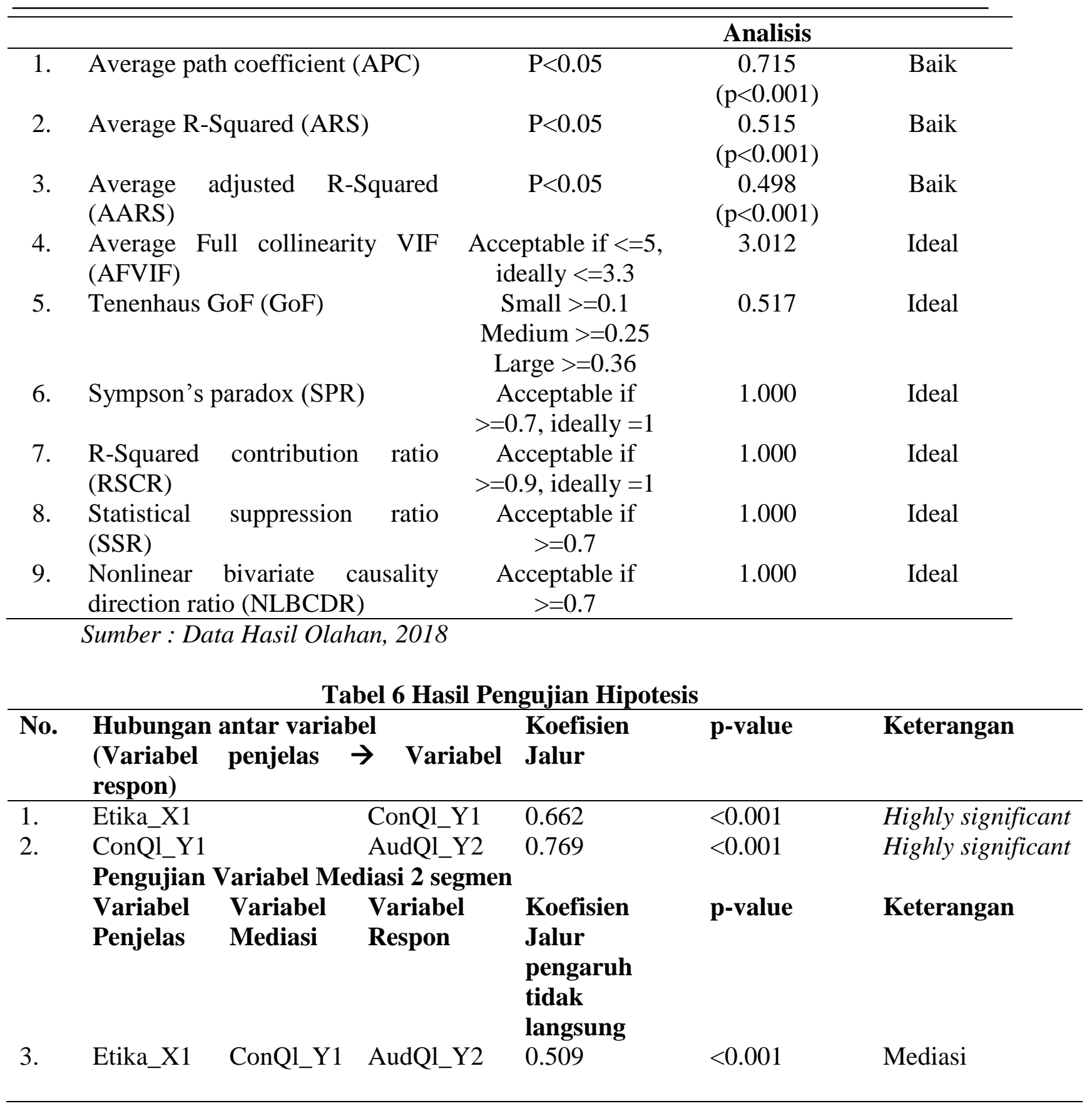

Tabel 7 Koefisien Jalur Pengaruh Total

\begin{tabular}{llll}
\hline No. Hubungan antar variabel & Koefisien & p-value & Keterangan \\
\hline
\end{tabular}




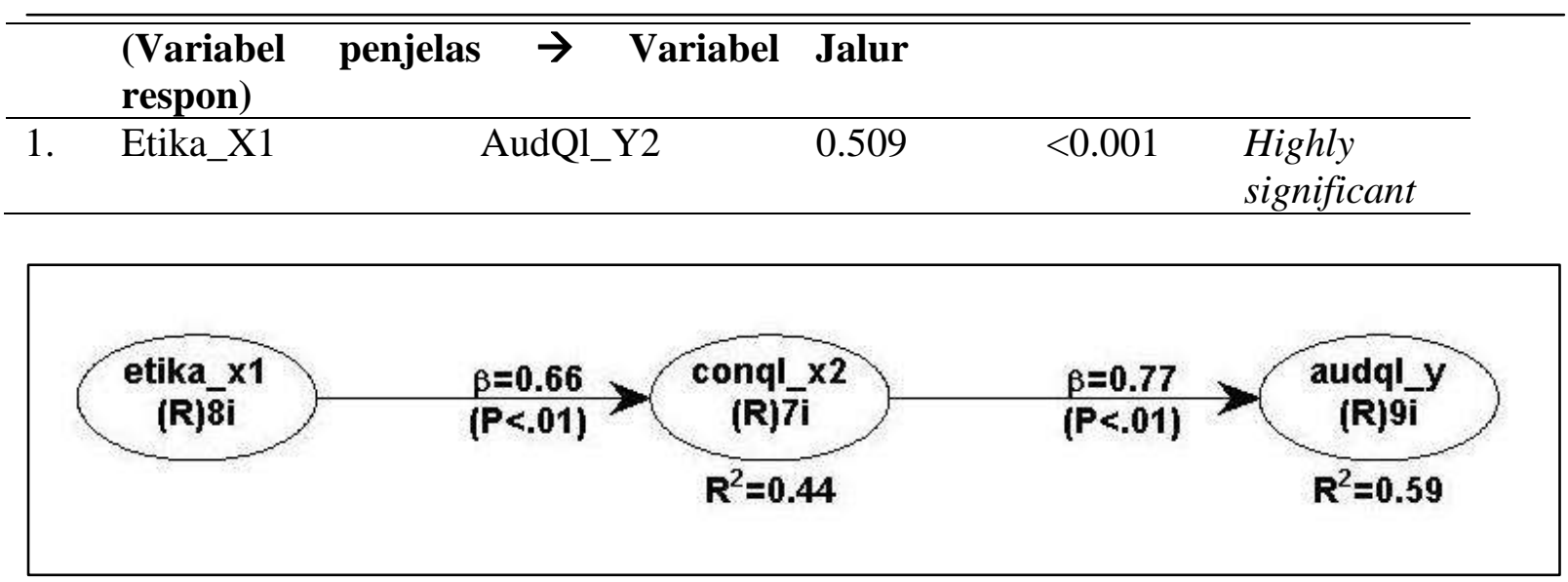

Gambar 2. Audit Quality Success Model

\subsection{Pembahasan}

Aturan Etika Berpengaruh terhadap Kualitas Audit. Human Capital Theory berasumsi bahwa modal manusia memiliki berbagai dimensi yang dikategorikan sebagai kelebihan-kelebihan yang dimiliki oleh individu, termasuk keahlian dan kemampuan, penampilan, reputasi, atau berupa sikap kepedulian terhadap kepentingan umum, sehingga memunculkan kepercayaan dari masyarakat. Dalam mewujudkan BPK yang memiliki sikap independen, berintegritas, dan profesionalisme bagi kepentingan negara, semua Anggota BPK dan Pemeriksa Keuangan Negara wajib melaksanakan kode etik. Oleh karena itu ketika auditor memiliki independensi, integritas dan profesionalisme yang tinggi, dia mampu memberikan hasil audit yang berkualitas melalui pelaporan yang andal dan kredibel.

Aturan Etika Berpengaruh terhadap Pengendalian Mutu. Etika merupakan suatu sikap dan perilaku yang memperlihatkan kesediaan dan kesanggupan individu secara sadar untuk mematuhi ketentuan dan norma yang berlaku pada suatu entitas. Semua hal yang membawa peningkatan bagi kualitas pekerjaannya akan ditelaah dengan baik dan seksama. Kegiatan-kegiatan seperti supervisi, review berjenjang, monitoring, dan konsultasi dalam pemeriksaan diharapkan menambah efektivitas pelaporan hasil pemeriksaan dan membantu lembaga perwakilan serta pemerintah untuk memperbaiki tata kelola. Ketika seorang auditor tahu bahwa ia memiliki potensi dalam dirinya, maka dia akan bekerja keras untuk mengembangkan dan mengelola potensi dalam dirinya dengan memastikan bahwa potensinya sudah sesuai dengan pemeriksaan yang dilakukannya. Auditor membutuhkan revisi, supervisi dan monitoring sebagai bentuk kepedulian akan efektivitas audit yang dihasilkan.

Pengendalian Mutu Berpengaruh terhadap Kualitas Audit. Meningkatkan kepercayaan para stakeholder terhadap hasil pemeriksaan BPK, memerlukan standar pengendalian mutu. Standar pengendalian mutu merupakan dasar guna menilai apakah kegiatan pemeriksaan berjalan sudah sesuai dengan standar pemeriksaan. Sistem pengendalian mutu merupakan seperangkat prosedur dan kebijakan yang diberlakukan guna memastikan kegiatan pemeriksaan telah sesuai dengan standar dan peraturan perundangundangan. Auditor wajib melaksanakan sistem pengendalian mutu saat penugasan guna memberikan keyakinan bagi pengguna laporan bahwa kegiatan Pemeriksaan telah sesuai dengan standar pemeriksaan serta aturan perundang-undangan, dan juga LHP sudah tepat berdasarkan kondisi yang terjadi selama proses audit. BPK memerlukan pengendalian mutu untuk memastikan kualitas hasil pemeriksaan yang dilakukan.

Aturan Etika Berpengaruh terhadap Kualitas Audit dengan Mediasi Pengendalian Mutu. Semua anggota BPK dan Pemeriksa dituntut melakukan kegiatan pemeriksaan berlandaskan aturan-aturan etika sebagai bagian yang penting dari nilai akuntabilitas serta harapan masyarakat kepada BPK dan Pemeriksa untuk melakukan 
kegiatan pemeriksaan. Dengan berpegang pada nilai akuntabilitas diharapkan bahwa kepercayaan publik dapat kembali meningkat. Kesadaran akan adanya kemampuan dalam diri akan membuat manusia termotivasi untuk bekerja dengan semangat untuk mencapai tujuannya. Demikian juga auditor, dengan adanya kesadaran adanya potensi yang baik dalam dirinya, dia akan termotivasi untuk lebih baik lagi. Teori harapan menjadi penjelas antara hubungan antara aturan etika terhadap kualitas audit dengan mediasi pengendalian mutu. Pengendalian mutu terdiri dari supervisi, review berjenjang, monitoring, serta kegiatan konsultasi selama kegiatan pemeriksaan. Sistem pengendalian mutu Badan Pemeriksa Keuangan (BPK) harus benar-benar bersandarkan standar pengendalian mutu agar supaya kualitas kegiatan pemeriksaan yang dilaksanakan selalu terjaga dengan baik.

\section{KESIMPULAN DAN SARAN}

\subsection{Kesimpulan}

Hasil penelitian ini menunjukkan bahwa aturan etika meningkatkan kualitas audit baik secara langsung maupun dimediasi oleh pengendalian mutu. Hasil ini memperkuat teori ekspektasi sebagai penjelas hubungan antara pengendalian mutu dan kualitas audit. Hal ini membuktikan bahwa konsep kualitas DeAngelo (1981) diterima dalam penelitian ini, dimana konsep ini menyatakan bahwa auditor harus mampu menemukan kesalahan/salah saji (dengan adanya potensi diri untuk melaksanakan aturan etika untuk memperoleh independensi, integritas dan profesionalisme dalam proses pemeriksaannya) dan kemudian harus melaporkannya kepada para pemangku kepentingan. Hasil penelitian ini juga menunjukkan bahwa modifikasi peneliti dengan memasukkan variabel mediasi pengendalian mutu menjadi perantara hubungan aturan etika terhadap kualitas audit. Auditor wajib melaksanakan sistem pengendalian mutu disaat penugasan guna memberikan keyakinan memadai yakni kegiatan Pemeriksaan telah sesuai dengan standar pemeriksaan dan undang-undang yang berlaku, dan laporan hasil pemeriksaan sudah tepat sesuai dengan kondisi saat pemeriksaan dilakukan. BPK memerlukan pengendalian mutu untuk memastikan kualitas hasil pemeriksaan yang dilakukan.

\subsection{Saran}

1. Bagi Auditor, kiranya penelitian ini menjadi perhatian dalam pengembangan kualitas profesional mereka, melihat pentingnya aturan etika, dan pengendalian mutu dalam meningkatkan kualitas audit.

2. Kiranya penelitian ini boleh menjadi masukkan yang baik bagi perkembangan standar pemeriksaan keuangan Negara dalam memberikan nilai tambah bagi masyarakat.

3. Untuk penelitian selanjutnya, mungkin bisa mempertimbangan audit file review sebagai suatu kegiatan untuk menambah efektivitas dari pelaporan hasil pemeriksaan dan membantu lembaga perwakilan serta pemerintah untuk memperbaiki tata kelola entitas.

\section{DAFTAR PUSTAKA}

Aldhizer, G. R., Miller, J. R., Moraglio, J. F. (1995). Common Attributes of Quality Audits. Journal of Accountancy. Vol.179 No.1 p. 61.

Badan Pemeriksa Keuangan Republik Indonesia. (2017). Standar Pemeriksaan Keuangan Negara. Jakarta

Bedard, J. C., Johnstone, K. M. (2010). Audit Partner Tenure and Audit Planning and Pricing. Auditing: A Journal of Practice \& Theory. Vol.29 No.2. $\mathrm{p} 45-70$.

Behn, B. K., Choi, J.-H., dan Kang, T. (2008). Audit Quality and Properties of Analyst Earnings Forecasts. The Accounting Review. Vol.83 No.2 p. 327-349. 
Bontis, N., Dragonetti, N. C., Jacobsen, K., Roos, G. (1999). The Knowledge Toolbox:: A Review of The Tools Available to Measure and Manage Intangible Resources. European management journal. Vol.17 No.4 p.391-402.

Carcello, J. V., Nagy, A. L. (2004). Audit Firm Tenure and Fraudulent Financial Reporting. Auditing: A Journal of Practice \& Theory. Vol.23 No.2 p. 55-69.

Carey, P., dan Simnett, R. (2006). Audit Partner Tenure and Audit Quality. The Accounting Review. Vol.81No.3 p. 653-676.

DeAngelo, L. E. (1981b). Auditor Size and Audit Quality. Journal of Accounting \& Economics. Vol.3 (December) p.183-199.

Deis, D. R., Giroux, G. A. (1992). Determinants of Audit Quality in the Public Sector. The Accounting Review. Vol.67 No.3. p. 462-179.

Dye, R.A. (1991). Informationally Motivated Auditor Replacement. Journal of Accounting \& Economics. Vol.14 p.347-374.

Elitzur, Ramy., Falk, Haim. (1996). Planned Audit Quality. Journal of Accounting and Public Policy. p.247-269.

Ghosh, A., Moon, D. (2005). Auditor Tenure and Perceptions of Audit Quality. The Accounting Review, Vol.80 No.2. p.585-612.

Lennox, Clives. (1999). Are Large Auditors More Accurate Than Small Auditors?. Accounting and Business Research. Vol.29. No.3. p.217-227.

Libby, R., Luft, J. (1993). Determinants of Judgment Performance in Accounting Settings: Ability, Knowledge, Motivation, and Environment. Accounting, Organizations and Society. Vol.18 No.5. p.425-450.

Palmrose, Z. (1988). An Analysis of auditor litigation and service quality. The Accounting Review. Vol.63 No.1. p.55-73.

Skinner, D. J., Srinivasan, S. (2012). Audit Quality and Auditor Reputation: Evidence from Japan. The Accounting Review. Vol.87 No.5 p.1737-1765.

Tribunnews. (2018). ICW : Ada 6 Kasus Suap yang Melibatkan Oknum Pejabat BPK dalam

Kurun Waktu 2015-2017. Jakarta. http://www.tribunnews.com/nasional/2017/05/27/icw-ada-6-kasus-suap-yangmelibatkan-oknum-pejabat-bpk-dalam-kurun-waktu-2015-2017 diakses tanggal 12 Desember 2018.

Tritschler, J. (2013). Audit Quality: Association Between Published Reporting Errors and Audit Firm Characteristics Austria: Springer Gabler.

Vroom, Victor. H. (1964). Work and Motivation. New York: John Willey\&Son, Inc. 